\title{
Microfibrillar elements in the synovial joint: presence of type VI collagen and fibrillin- containing microfibrils
}

\author{
Andrew D Waggett, Cay M Kielty, C Adrian Shuttleworth
}

\begin{abstract}
Objectives-The aims were to isolate and positively identify the microfibrillar elements which have been observed in the synovial lining. In addition, synovial fluid was examined for these elements to improve the understanding of the role of these structures in health and disease.

Methods-Bacterial collagenase digestion of bovine synovial linings and human and bovine synovial fluids was used to release intact, non-denatured microfibrillar elements. The microfibrils were isolated by Sepharose CL-2B chromatography and viewed by rotary shadowing. They were characterised by immunogold labelling with specific antibodies.

Results-Intact type VI collagen microfibrils and fibrillin-containing microfibrils were isolated and positively identified in the synovial lining from bovine ankle joints by immunogold labelling. Type VI collagen microfibrils were also present in the synovial fluid.

Conclusions-The role of the microfibrillar elements in vivo is not fully understood, but their distribution in the synovial lining suggests they have an important role in the mechanical and physical properties of this tissue. The presence of type VI collagen microfibrils in synovial fluid poses the intriguing possibility that it may represent a product of microfibril turnover and a potential early marker for rheumatoid arthritis. Alternatively, type VI collagen may be specifically secreted into the synovial fluid to interact with hyaluronan and form part of the structure of synovial fluid.
\end{abstract}

(Ann Rheum Dis 1993; 52: 449-453)

Department of Biochemistry and Molecular Biology, School of Biological Sciences,

University of

Manchester,

Oxford Road,

Manchester M13 9PT, United Kingdom

A D Waggett

C M Kielty

C A Shuttleworth

Correspondence to: Dr Waggett.

Accepted for publication 28 January 1993 the structural and functional integrity of joint. It is responsible for synthesising and secreting hyaluronan and other molecules important for lubrication into the synovial fluid, and provides a blood supply for chondrocytes in the avascular cartilage.

The synovial lining has been relatively poorly characterised at the biochemical level despite the key role of this tissue in the functioning of the joint. It consists of a loose network of cells embedded in a collagenous interstitium through which solutes pass into the synovial fluid. ${ }^{1}$ Histochemical analyses have shown the synovial lining to contain a number of structural macromolecules including collagens, ${ }^{23}$ proteoglycans, ${ }^{4-6}$ fibronectin, ${ }^{37}$ hyaluronan, ${ }^{8} 9$ and microfibrils. ${ }^{1011}$

The distribution of collagens in the synovial lining appears to be unique. Type IV collagen is found in the vascular basement membranes ${ }^{3}$ and cellular basement membranes ${ }^{12}$ of the synovial lining. Type $\mathrm{V}$ collagen is present throughout the matrix of the synovial lining. ${ }^{13}$ Types I and III collagens, which form $67 \mathrm{~nm}$ banded fibres, predominate in the deeper regions of the synovial lining. In contrast with other tissues, where type VI microfibrils and type I collagen fibres interact, in the region of the synovial lining directly adjoining the synovial cavity the fibrillar collagens are largely absent, but this region is particularly rich in microfibrils.

There are two distinct and unrelated classes of connective tissue microfibrils. These are the type VI collagen microfibrils and the fibrillincontaining microfibrils, both of which have a widespread tissue distribution. Type VI collagen microfibrils are formed from triple helical monomers of type VI collagen which assemble laterally to form dimers and then tetramers. These associate in an end to end fashion to form extensive double beaded microfibrils with a periodicity of $100 \mathrm{~nm}$ and a diameter of 3-5 nm. ${ }^{14}$ The glycoprotein fibrillin is the principal structural component of a second distinct class of microfibrils which have a diameter of $10-13 \mathrm{~nm}$ and an average periodicity of $50 \mathrm{~nm} \cdot{ }^{15}$ In elastic tissues the fibrillin-containing microfibrils play a key part in elastogenesis ${ }^{16}$ and in vitro studies have shown that fibrillin-containing microfibrils can support cell adhesion. ${ }^{17}$ No specific role for these microfibrils has yet been demonstrated in non-elastic tissues, however.

Histochemical studies have shown the presence of microfibrils in the synovial lining. ${ }^{10}$ In addition, broad, banded aggregates (possibly consisting of microfibrils) called fibrous long spacing material have been reported in the synovial lining. ${ }^{6}$ These microfibrillar 
elements and the fibrous long spacing structures have been tentatively identified as type VI collagen. ${ }^{11}$

We describe here the presence of type VI collagen microfibrils and fibrillin-containing microfibrils in synovial lining and type VI collagen microfibrils in synovial fluid.

\section{Materials and methods}

TISSUE EXTRACTION AND DISSOLUTION

Microfibrillar preparations from the synovial lining of adult bovine ankle joints were prepared as previously reported. ${ }^{19}$ The dissolved material was clarified by centrifugation at $10000 \mathrm{~g}$ for 30 minutes and applied directly to a Sepharose CL-2B column (PharmaciaLKB).

Samples of synovial fluid were obtained from fetal bovine knee joints and human osteoarthritic joints. For the synovial fluid an equal volume of $50 \mathrm{mM}$ TRIS- $\mathrm{HCl}, \mathrm{pH} 7 \cdot 4$, containing $0.4 \mathrm{M} \mathrm{NaCl}, 0.01 \mathrm{M} \mathrm{CaCl}_{2}, 2 \mathrm{mM}$ phenylmethanesulphonyl fluoride (Sigma Chemical), $10 \mathrm{mM}$ N-ethylmaleimide (Sigma Chemical), which also contained $0.5 \mathrm{mg}$ bacterial collagenase (type 1A, Sigma Chemical) was added before incubation at $4^{\circ} \mathrm{C}$ for 18 hours. The reaction was terminated by the addition of $10 \mathrm{mM}$ EDTA, clarified by centrifugation, and applied directly to a Sepharose CL-2B column for gel filtration chromatography.

The synovial lining samples were chromatographed directly without concentration under non-reducing, non-denaturing conditions on a column $(3 \times 75 \mathrm{~cm})$ of Sepharose CL-2B equilibrated with $50 \mathrm{mM}$ TRIS- $\mathrm{HCl}, \mathrm{pH} 7 \cdot 4$, containing $0.4 \mathrm{M} \mathrm{NaCl}$ at a flow rate of $12 \mathrm{ml} /$ hour. The synovial fluid solution was chromatographed on a column $(1 \cdot 2 \times 20 \mathrm{~cm})$ of Sepharose CL-2B equilibrated in the same buffer at a flow rate of $8 \mathrm{ml} /$ hour. Column effluents were monitored at $230 \mathrm{~nm}$. In each instance fractions were collected and pooled as appropriate. The pooled fractions which contained high molecular weight material eluting at or near the void volume were used for rotary shadowing electron microscopy and immunogold labelling.

ROTARY SHADOWING ELECTRON MICROSCOPY The contents of each of the high molecular weight pooled fractions from the Sepharose CL-2B column were determined by rotary shadowing electron microscopy using the mica sandwich technique. ${ }^{19} 20$

IMMUNOGOLD ELECTRON MICROSCOPY Immunogold-protein complexes were prepared as previously described. ${ }^{21}$ Solutions were routinely filtered using $0.2 \mu \mathrm{m}$ filters. Void volume samples $(10 \mathrm{ml})$ were extensively dialysed against $20 \mathrm{mM}$ magnesium acetate and placed in a PTFE dish. A small amount $(<1 \mu \mathrm{l})$ of a $1 \mathrm{mg} / \mathrm{ml}$ solution of benzyldimethylalkylammonium chloride was taken up into a pipette tip and touched onto the sample to form a thin film on the surface of the sample. After 20 minutes molecules were picked up onto the nickel grids by touching the surface of a grid onto the surface of the benzyldimethylalkylammonium chloride.

Grids were dried by dipping in absolute ethanol, blotting onto filter paper and blocked in $5 \mathrm{mM}$ magnesium acetate $/ 0 \cdot 1 \%$ Tween 20 before being incubated in primary antibody (diluted 1:500 in $5 \mathrm{mM}$ magnesium acetate/ $0 \cdot 1 \%$ Tween 20) for one hour at room temperature. The antibodies to type VI collagen and fibrillin were as described previously. ${ }^{22}$ After washing four times for one minute each in $5 \mathrm{mM}$ magnesium acetate/ $0 \cdot 1 \%$ Tween 20 they were incubated in a $5 \mathrm{~nm}$ goldprotein A conjugate solution (diluted tenfold in $5 \mathrm{mM}$ magnesium acetate $/ 0 \cdot 1 \%$ Tween 20 ; TAAB Laboratory Equipment) for one hour at room temperature. Grids were washed in 5 $\mathrm{mM}$ magnesium acetate $/ 0 \cdot 1 \%$ Tween 20 and finally in $5 \mathrm{mM}$ magnesium acetate, dried by dipping into absolute ethanol, rotary shadowed using a platinum wire on a tungsten filament at an angle of $8^{\circ}$, and viewed under a JEOL 1200 EX electron microscope at $120 \mathrm{kV}$.

\section{Results}

Bacterial collagenase digestion of synovial lining homogenates removes the fibrillar collagens and effectively dissolves the microfibrillar components under non-reducing and non-denaturing conditions. ${ }^{19}$ Large macromolecular microfibrillar assemblies could be separated from plasma proteins and collagenous fragments on Sepharose CL-2B columns.

Rotary shadowing of the high molecular weight material obtained from the synovial lining from the adult bovine ankle joints showed the presence of type VI collagen microfibrils and fibrillin-containing microfibrils (fig 1A). These microfibrillar elements could also be isolated from the synovial lining of second and third trimester bovine fetal knee joints and porcine knee joints (results not shown).

Fibrillin and type VI collagen were present as extensive microfibrillar structures up to several micrometres in length. Type VI collagen microfibrils were consistently observed in more abundant amounts than the fibrillin-containing microfibrils in all the preparations. The type VI collagen microfibrils were flexible, double beaded microfibrils with a periodicity of $100 \mathrm{~nm}$, consistent with previous observations. ${ }^{19}$ In some instances lateral alignment of these microfibrils was apparent (fig 1B). The fibrillin-containing microfibrils had a distinctive morphology and were clearly distinct from the type VI collagen microfibrils. These assemblies were characterised by a single beaded periodicity of approximately $50 \mathrm{~nm}$ and a diameter of 10-12 nm. (fig 1A).

The morphological characteristics were clearly indicative of type VI collagen microfibrils and fibrillin-containing microfibrils and these were positively identified by 

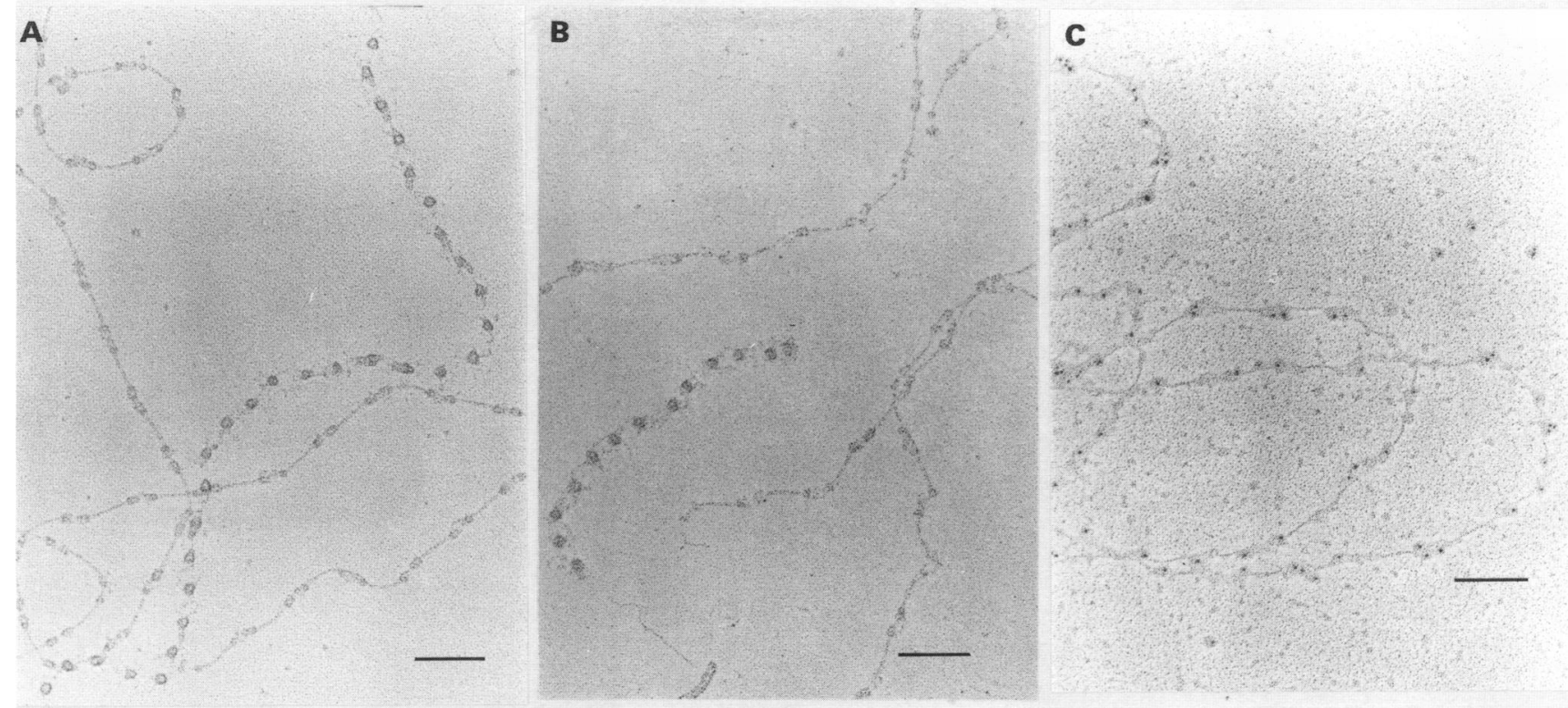

D
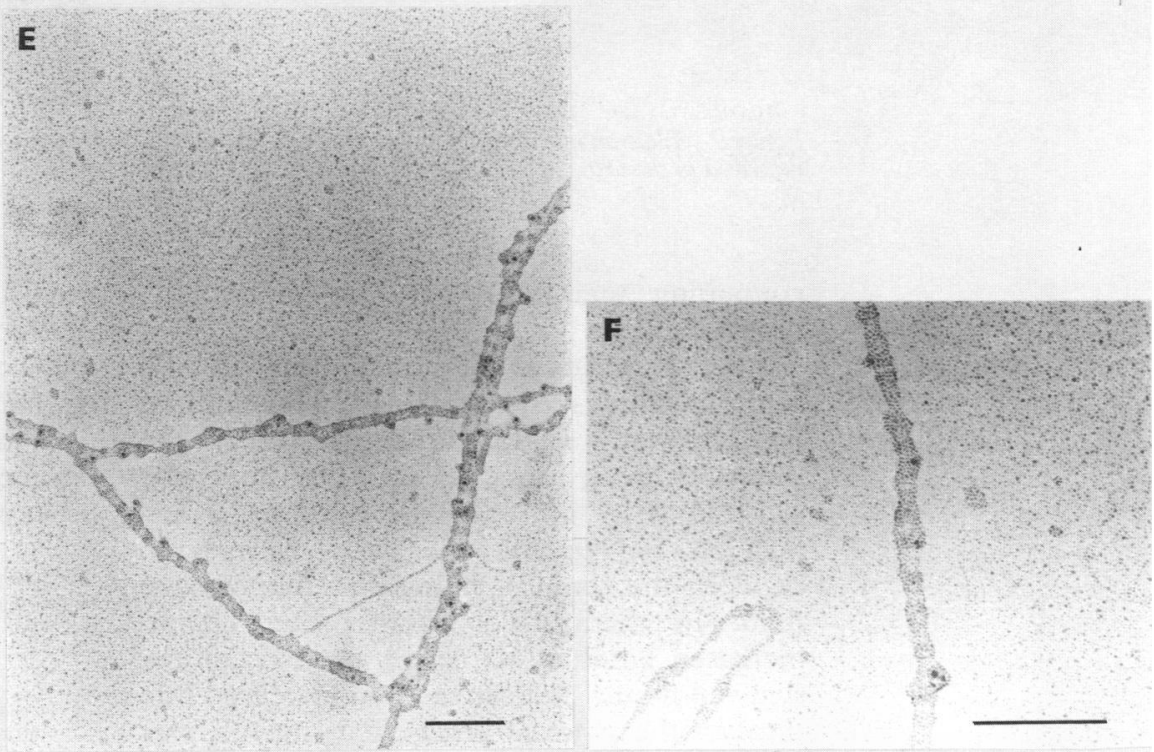

Figure 1 Electron micrographs after rotary shadowing of type VI collagen and fibrillin-containing microfibrils. $(A, B)$ Microfibrillar preparation isolated from synovial lining as described in the text. (C,D) Immunogold localisation of type VI collagen antibody (see Shuttleworth et al ${ }^{22}$ for details) as described in the text. (E, F) Immunogold localisation of fibrillin antibody (see Shuttleworth et al ${ }^{22}$ for details) as described in the text. Bars=100 $\mathrm{nm}$.

immunogold labelling. The antibodies against type VI collagen microfibrils recognised a number of epitopes on the $\mathrm{N}$ - and $\mathrm{C}$-terminal globular domains of the molecule as shown by the periodic distribution of gold particles (fig 1C). In a few instances two to three gold particles could be seen bound at the globular domains of these type VI collagen microfibrils. No staining was apparent on the fibrillin-containing microfibrils (fig 1D). The polyclonal antibodies to fibrillin bound predominantly to one side of the globular domains of these microfibrils (fig 1E). In general, antibody localisation disrupted the morphology of the fibrillin-containing microfibrils and was associated with one gold particle. The apparent lateral association of the microfibrils may be a consequence of antibody interactions, but further work will be required to resolve this possibility. No immunogold particles could be seen on juxtaposed type VI collagen microfibrils (fig $1 \mathrm{~F}$ ).

Fractionation of bacterial collagenase digests of fetal bovine and human osteoarthritic synovial fluids by Sepharose CL-2B chromatography showed that, compared with synovial lining digests, only a small amount of high molecular weight protein could be recovered in the void volume fractions. For bovine tissue, however, rotary shadowing electron microscopic analysis showed that this fraction contained type VI collagen microfibrils with characteristic periodicity and dimensions (fig $2 \mathrm{~A}$ ). A number of microfibrillar aggregates could be seen in adult human synovial fluid, some of which had an apparent periodicity similar to type VI collagen (fig 2B).

\section{Discussion}

Histochemical studies of synovial lining tissue showed the presence of microfibrillar elements. ${ }^{1011}$ We isolated and characterised microfibrils in their native, non-denatured state. Using this technique we have shown that type VI collagen microfibrils and fibrillin- 

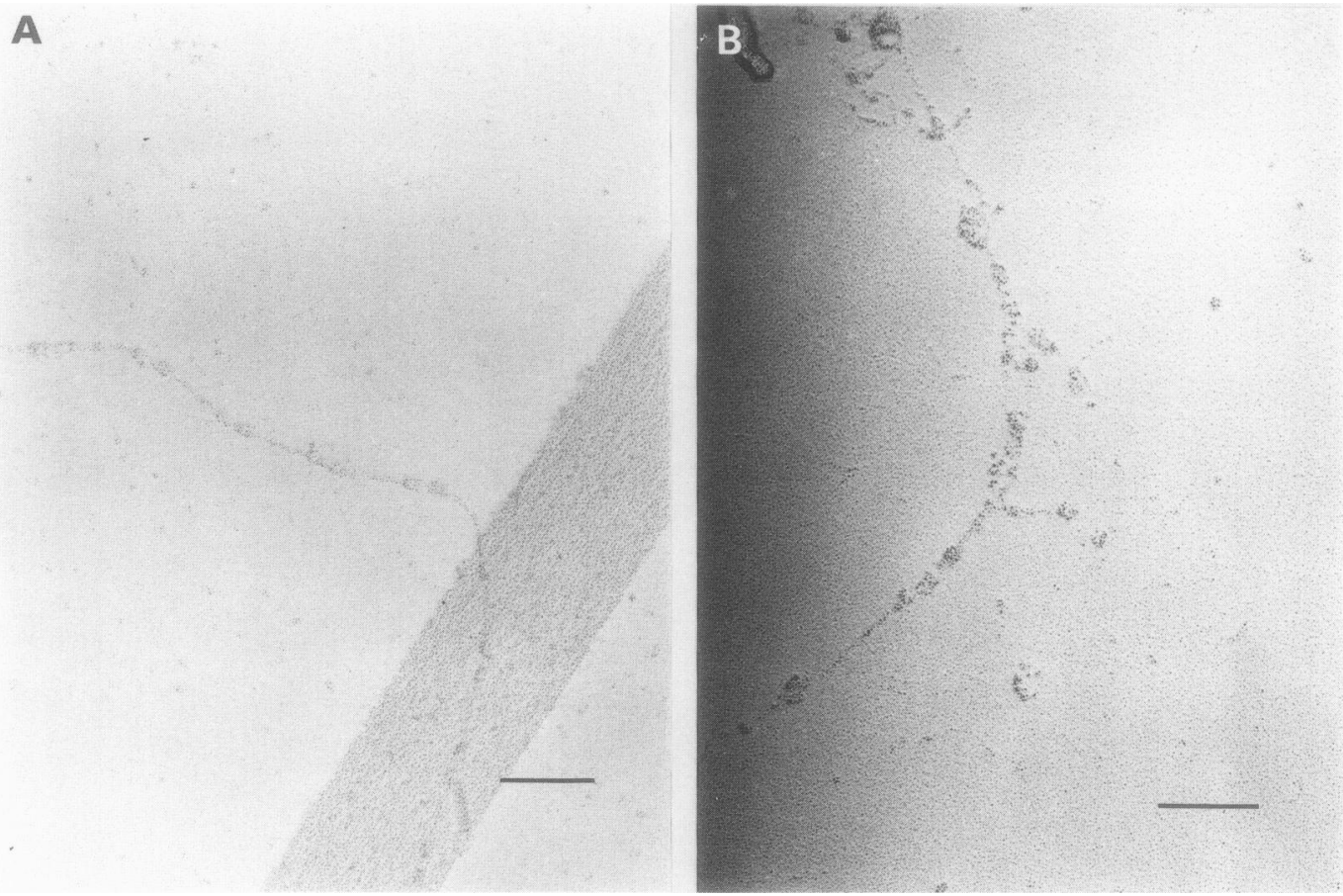

Figure 2 Electron micrographs after rotary shadowing of type VI collagen microfibrils isolated from synovial fluid as described in the text. (A) Bovine; (B) human. Bars $=100 \mathrm{~nm}$.

containing microfibrils are present in the synovial lining.

The distribution of microfibrils in the synovial lining is specific. ${ }^{11}$ They are located predominantly at the inner surface of the synovial lining directly abutting onto the synovial fluid and are therefore in a key position to regulate the flow of material between the synovial lining and the synovial fluid. In rheumatoid arthritis there is an increased amount of plasma proteins in the synovial fluid, ${ }^{23}$ indicative of an increased flux through the synovial lining. This may in part be due to the disruption of the normal organisation of this microfibrillar layer.

Interestingly, we have shown that small amounts of type VI collagen microfibrils are present in synovial fluid. These microfibrils have been shown to bind to hyaluronan ${ }^{24}$ and may be related to the organisation of hyaluronan, which is found in great abundance in the synovial fluid. At this stage it is unclear as to the origin of type VI collagen microfibrils in the synovial fluid. They may be present in the synovial fluid merely as a result of type VI collagen turnover in the synovial lining. Alternatively, these type VI collagen microfibrils may be secreted specifically into the synovial fluid from cells present in the synovial fluid or from cells in the neighbouring synovial lining. It is already known that cells in the synovial lining are responsible for the secretion of hyaluronan and other molecules into synovial fluid and it seems equally feasible that these cells may secrete microfibrils into the synovial fluid.

The presence and location of microfibrillar elements in the synovial lining suggests that these may be critical determinants of the function of this tissue. In addition, the presence of type VI collagen in the synovial fluid holds the tantalising possibility that this molecule represents an early marker in the disease process. It is clear that further work will be required to define the nature and role of the microfibrillar elements, but also to indicate any relevance of these molecules to the disease process.

We thank the Arthritis and Rheumatism Council for financia support (grant No 50118) and Stephen P Whittaker and Lind Berry for their expert technical assistance.

1 Levick J R. Synovial fluid exchange-a case of flow through fibrous mats. News Physiological Sciences 1989; 4 198-202.

2 Castor C W, Muirden K P. Collagen formation in monolayer cultures of human fibroblasts. The effects of hydrocortisone. Lab Invest 1964; 13: 560-6.

3 Linck G, Stocker S, Grimaud J-A, Porte A. Distribution of immunoreactive fibronectin and collagen (type I, III, IV) in mouse joints. Fibronectin, an essential component of the synovial cavity border. Histochemistry 1983; 77 323-8.

4 Castor C W, Roberts D J, Hossler P A, Bignall M C. Connective tissue activation. XXV. Regulation of proteoglycan synthesis in human synovial cells. Arthritis proteoglycan synthesis in

5 Fife R S, Myers S L. Evidence for an interaction between canine synovial cell proteoglycans and link proteins. Biochim Biophys Acta 1985; 843: 238-44.

6 Okado Y, Nakanishi I, Kajikawa K. Ultrastructure of the mouse synovial membrane. Development and organisation of the extracellular matrix. Arthritis Rheum 1981; 24 835-43.

7 Mapp P I, Revell P A. Fibronectin production by synovia intimal cells. Rheumatol Int 1985; 5: 229-37.

8 Hamerman D, Ruskin J. Histologic studies on human synovial membrane. 1. Metachromatic staining and the effects of streptococcal hyaluronidase. Arthritis Rheum 1959; 2: 546-52

9 Roy S, Ghadially F N. Synthesis of hyaluronic acid by synovial cells. F Pathol Bacteriol 1962; 93: 555-64.

10 Highton T C, Myers D B, Rayns D G. The intercellular spaces of synovial tissue. $N Z$ Med 7 1968; 67: 315-25.

11 Levick J R, McDonald J N. Microfibrillar meshwork of the synovial lining and associated broad banded collagen: a clue to identity. Ann Rheum Dis 1990; 49: 31-6.

12 Pollock L E, Lalor O, Revell P A. Type IV collagen and laminin in the synovial intimal layer: an immunohistochemical study. Rheumatol Int 1990; 9: 277-80.

13 Ashhurst D E, Bland Y S, Levick J R. An immunohistochemical study of the collagens of rabbit immunohistochemical study of the collagens of rab

14 Engvall E, Hessle H, Klier G. Molecular assembly, secretion and matrix deposition of type VI collagen. $\mathcal{f}$ Cell Biol 1986; 102: 703-10. 
15 Keene D R, Maddox B K, Kuo H-J, Sakai L Y, Glanville $R$ W. Extraction of extendible beaded structures and their identification as fibrillin-containing extracellular matrix microfibrils. I Histochem Cytochem 1991; 39: 441-9.

16 Fahrenbach W H, Sandberg L B, Cleary E G. Ultrastructural studies on early elastogenesis. Anat Rec 1966; 155: 563-75.

17 Kielty C M, Whittaker S P, Grant M E, Shuttleworth C A Attachment of human vascular smooth muscle cells to intact microfibrillar assemblies of collagen VI and fibrillin. intact microfibrillar assemblies

18 Linck G, Porte A. B-cells of the synovial membrane. III. Relationship with the specific collagenous structure of the intimal interstitium in the mouse. Cell Tissue Res 1981, 218: $117-21$

19 Kielty C M, Cummings C, Whittaker S P, Shuttleworth C $A$, Grant M E. Isolation and ultrastructural analysis of microfibrillar structures from foetal bovine elastic tissues. Relative abundance and supramolecular architecture of type VI collagen assemblies and fibrillin. $\mathcal{F}$ Cell Sci 1991;
99: 797-807.

20 Mould A P, Holmes D F, Kadler K E, Chapman J A. Mica sandwich technique for preparing macromolecules for rotary shadowing. Fournal of Ultrastructural Research 1985; 91: $66-76$.

21 Sheehan J K, Oates K, Carlstedt I. Electron microscopy of cervical, gastric and bronchial mucus glycoproteins. Biochem f 1986; 239: 147-53.

22 Shuttleworth C A, Berry L, Kielty C M. Microfibrillar components in dental pulp: presence of both type VI Biol 1992; 37: 1079-84.

23 Levick J R. The permeability of rheumatoid and normal human synovium to specific plasma proteins. Arthritis Rheum 1981; 24: 1550-60

24 Kielty C M, Whittaker S P, Grant M E, Shuttleworth C A Type VI collagen microfibrils: evidence for a structura association with hyaluronan. If Cell Biol 1992; 118: 979-90. 